SATIN - Sains dan Teknologi Informasi

\title{
Rancang Bangun Prototipe Aplikasi Penunjang Keputusan Joint Venture dengan Metode Analytical Hierarchy Process (Studi Kasus: CV. ABC)
}

\author{
Cynthia Hayat \\ Universitas Kristen Krida \\ Wacana \\ cynthia.hayat@ukrida.ac.id
}

\author{
Hansen \\ Universitas Kristen Krida \\ Wacana \\ hansen.2012si005@ukrida.ac.id
}

\author{
Afrido Vadri Hutapea \\ PT.Restu Mahkota \\ Karya \\ afrido@mahkota.info
}

\begin{abstract}
$C V . A B C$ is a company engaged in the field of import and export. In the face of competition, ABC companies change their business strategies by globalizing, marked by direct investment in the company's operations, or better known as joint ventures. Development of decision support applications using analysis with the process of hierarchy analysis $(A H P)$ and prototyping methods, or better known as the iterative process. In making decisions, compared to a number of things that are factual with the expectations of the company. What is compared is the total imports, total exports and total suppliers with the expectation determined by the company. From these comparisons resulted in several variations of answers, namely very ready, less ready, very less ready and not ready to do a joint venture.
\end{abstract}

Keywords: Joint venture, AHP, SPK

\begin{abstract}
Abstrak
CV. ABC adalah sebuah perusahaan yang bergerak dalam bidang ekspor impor. Dalam menghadapi persaingan, perusahaan $\mathrm{ABC}$ mengubah strategi bisnis mereka dengan melakukan globalisasi ditandai dengan investasi langsung pada operasional perusahaan atau yang lebih dikenal dengan joint venture. Pengembangan aplikasi penunjang keputusan menggunakan analisa dengan proses hierarki analisis (AHP) dan metode
\end{abstract}

prototyping atau lebih dikenal dengan proses berulang. Dalam mengambil keputusan, dibandingkan beberapa hal yang faktual dengan harapan dari pihak perusahaan. Hal yang dibandingkan adalah total impor, total ekspor dan total supplier dengan angka harapan yang ditentukan oleh perusahaan. Dari perbandingan tersebut menghasilkan beberapa variasi jawaban, yaitu sangat siap, kurang siap, sangat kurang siap serta tidak siap melakukan joint venture.

Kata Kunci : Joint venture, AHP, SPK

\section{Pendahuluan}

Kebutuhan akan adanya kemudahan, keefektifan serta keefisienan dalam pelaksanaan proses kerja dalam perusahaan membuat perusahaan merubah alur bisnis mereka. Hal ini juga diharapkan akan memudahkan perusahaan dalam pelaksanaan proses bisnis serta menjadi nilai tambah bagi perusahaan dalam melakukan proses-proses yang dilakukan.[1]

CV.ABC adalah sebuah perusahaan yang bergerak dalam bidang ekspor impor transaksi barang atau komoditas yang dilakukan dari suatu negara ke negara lainnya. Dalam menghadapi persaingan, perusahaan ABC mengubah strategi bisnis mereka dengan melakukan globalisasi ditandai dengan investasi langsung pada operasional perusahaan. Mengacu pada UU No.25 tahun 2017, joint venture dapat dikategorikan sebagai bentuk kegiatan penanaman modal asing dengan tujuan memberikan kekuatan ekonomi kepada 
perusahaan induk sehingga mendapatkan keuntungan bersama. Joint Venture juga dapat didefinisikan sebagai penyusunan resmi antara dua atau lebih perusahaan untuk menciptakan bisnis baru untuk tujuan dalam mendapatkan keuntungan bersama, seringkali membahas pengembangan bisnis, dan pengembangan produk dan pasar baru.[2][3]

Little mendefinisikan SPK sebagai "sekumpulan prosedur berbasis model untuk pemrosesan data dan perkiraan untuk membantu manajer dalam membuat keputusan." [4][5] Metode Analytical Hierarchy Process (AHP) yang digunakan pada pengembangan aplikasi penunjang keputusan untuk mengorganisasikan hasil informasi dan dugaan dalam memberikan alternatif terbaik. Metode AHP juga dapat digunakan untuk menyelesaikan masalah yang bersifat kompleks dan tidak terstruktur dimana dibuat dalam sebuah struktur yang berhierarki dari kriteria yang dipilih sampai pada sub-sub kriteria yang paling dalam.[6][7][8] Perhitungan validitas dilakukan sampai batas toleransi inkonsentrasi sebagai kriteria dan alternatif yang dipilih oleh para pengambil keputusan.[9][10]

Sehingga metode AHP dipilih karena model yang komperehensif sehingga pembuat keputusan dapat menetukan pilihan atas pasangan perbandingan yang sederhana, membangun semua prioritas untuk urutan alternatif. Sehingga diharapkan dapat membantu pihak perusahaan dalam menentukan keputusan dalam melakukan joint venture dan memberikan dukungan terkomputerisasi dalam melakukan pencatatan data eksport impor barang, memberikan statistik data, serta menjadi penunjang keputusan joint venture.[11][12]

\section{Metode Penelitian}

\subsection{Pengumpulan Data}

Jenis data yang dipakai di dalam penelitian ini adalah data primer dan sekunder. Data primer yang digunakan adalah hasil observasi beserta data-data, seperti data eksport, import, pegawai, supplier serta permasalahan yang terjadi pada perusahaan. Sedangkan, data sekunder yang digunakan adalah data yang didapat dari studi pustaka, yaitu data-data teori serta pendukung. Metode yang digunakan dalam pengambilan data terbagi atas 2 metode yang digunakan, yaitu:

1. Studi Literatur

Studi litelatur berarti data yang diperlukan dalam pelaksanaan penulisan ini diambil dari buku-buku yang diambil dari beberapa sumber, baik dalam bentuk digital maupun dalam bentuk buku. Data yang diambil dapat dalam bentuk bahan ajar, skripsi, karya ilmiah, ebook maupun buku teori.

2. Studi Lapangan
Studi lapangan dilakukan dalam mendapatkan data yang dibutuhkan berdasarkan data yang didapat langsung dari lapangan. Data-data yang didapat langsung dari lapangan berupa proses bisnis, datadata yang diproses oleh perusahaan, orang-orang yang berhubungan dengan proses, serta masalah yang dihadapi oleh perusahaan. Dalam pelaksanaan di perusahaan ekspor impor, data yang diperlukan adalah seperti berikut:

1. Data Ekspor Barang,

Data ekspor barang berarti segala jenis data yang berhubungan dengan semua jenis barang yang di ekspor ke luar negeri.

2. Data Impor Barang,

Data impor barang membahas semua jenis data yang berhubungan dengan jenis barang yang masuk ke perusahaan.

3. Data Supplier,

Supplier didata dengan upaya mengetahui supplier mana yang memberikan barang dengan jumlah yang memenuhi kebutuhan.

4. Data Pekerja di perusahaan,

Data pekerja di perusahaan diperlukan agar mengetahui bagian mana saja yang berhubungan dengan aplikasi yang dibuat nantinya.

5. Permasalahan Joint Venture.

Permasalahan ini adalah hal yang harus diselesaikan dengan adanya pendukung keputusan yang dibuat oleh penulis.

\subsection{Desain Penelitian}

Analisa yang dilakukan dalam perancangan ini adalah metode analisa yang bersifat kualitatif yang berarti proses bisnis dari perusahaan digambarkan ke dalam proses bisnis baru melalui DFD dan ERD dan membandingkan kegunaan dari kedua proses bisnis tersebut. Yang menjadi parameter keberhasilan adalah jika proses bisnis baru lebih efisien dan efektif dibandingkan dengan proses bisnis lama dari perusahaan ekspor impor.

Proses bisnis dimulai dengan menbuat daftar supplier kemudian menerima import barang dan permintaan ekspor barang. Setelah permintaan ekspor dan impor barang telah diterima, dilakukan pengecekan jumlah barang yang tersedia. Jika jumlah barang yang diinginkan tersedia maka akan dilakukan ekspor barang dan jika jumlah barang uang diinginkan tidak tersedia maka akan perusahaan akan melakukan permintaan barang dan kembali mngulang proses penerimaan barang import. Gambar 1 di bawah ini menjelaskan proses bisnis yang dilakukan oleh CV.ABC. 


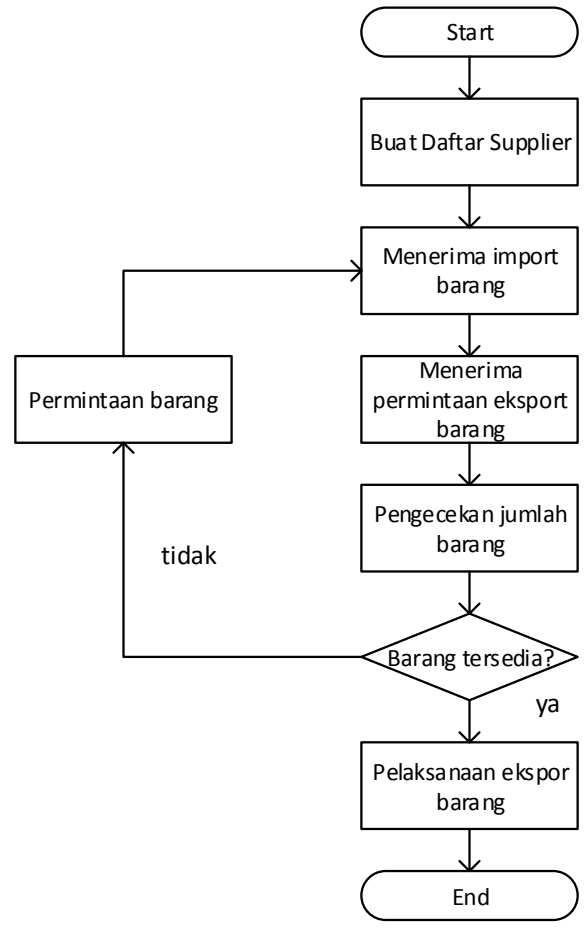

Gambar 1 Flowchart Proses bisnis perusahaan

Proses bisnis perusahaan dimulai dengan membuat daftar supplier kemudian menerima import barang berupa permintaan ekspor. Sebelumnya dilakukan pengecekan barang apakah barang tersedia. Jika barang tersedia, maka akan dilakukan ekspor dan jika barang tidak tersedia, makan akan melakukan permintaan barang kembali.

\subsection{Analisis DFD}

Data Flow Diagram atau lebih dikenal dengan DFD digunakan untuk menggambarkan aplikasi yang akan dikembangkan ke dalam sebuah jaringan proses fungsional yang dihubungkan satau sama lain dengan alur data.[13] Analisa DFD pada aplikasi penunjang keputusan joint venture dijabarkan menggunakan diagram konteks seperti gambar 2 di bawah ini dan diagram level 1seperti gambar 3 di bawah ini

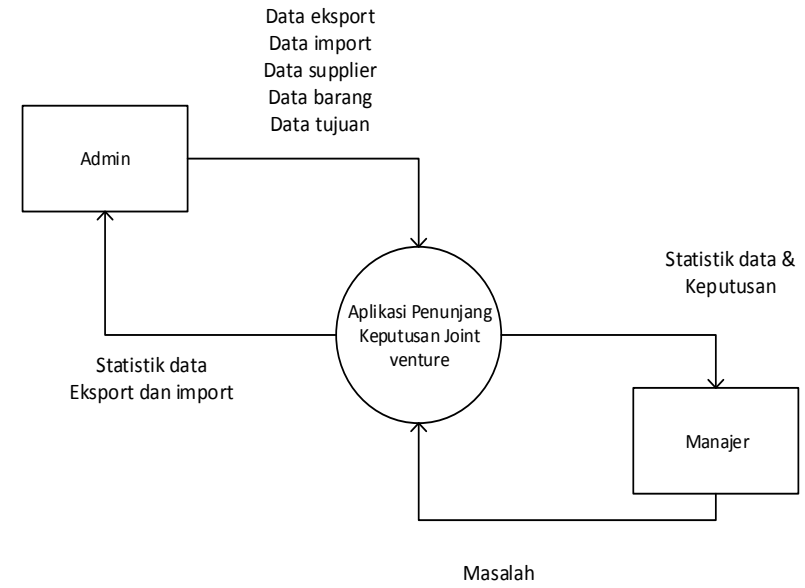

Gambar 2 Diagram Konteks

Diagram konteks adalah diagram yang menggambarkan ruang lingkup system secara keseluruhan yang direpresentasikan ke dalam sistem input dan output. Pada diagram konteks di atas terlihat aplikasi penunjang keputusan berinteraksi dengan user admin dan user manajer yang nantinya akan menggunakan aplikasi tersebut. Pada user admin akan dapat mengakses data ekspor, data impor, data supplier, data barang, dan data tujuan ke aplikasi dan akan menerima statistik data ekspor dan impor dari aplikasi. Sedangkan dari user manajer akan menginput masalah yang ada ke aplikasi kemudian aplikasi akan memberikan output berupa statistik datan dan keputusan dari masalah yang ada yaitu keputusan joint venture.

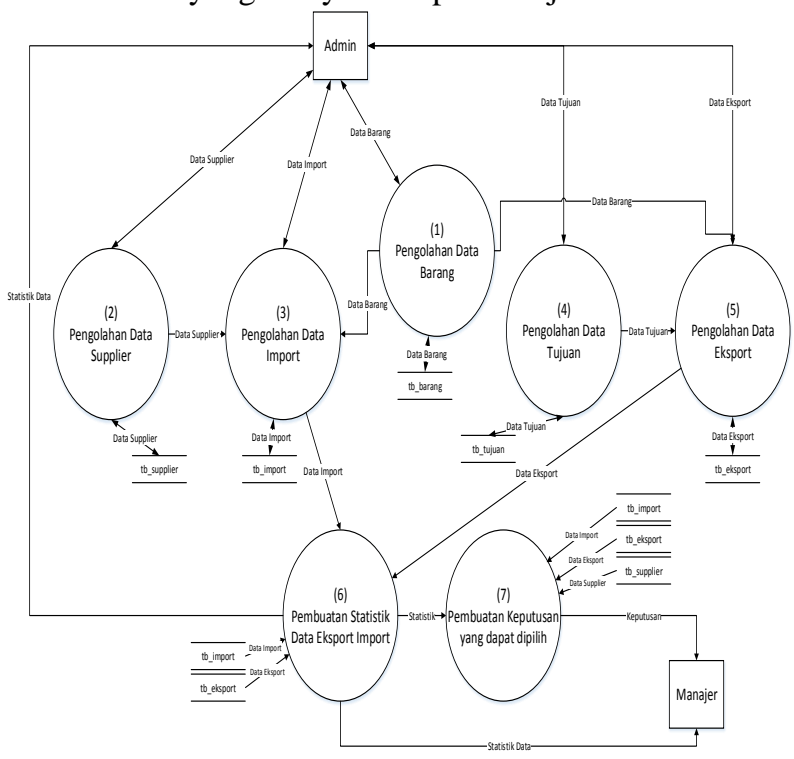

Gambar 3. Diagram Level 1 
Diagram level 1 menunjukkan proses-proses utama yang terjadi di dalam sistem yang sedang dibangun. Diagram level 1 merupakan pengembangan lebih rinci dari diagram konteks. Apada aplikasi penunjang keputusan dilakukan proses pengolahan data supplier, pengolahan data import, pengolahan data barang, pengolahan data tujuan, pengolahan data ekspor, pembuatan statistik data eksport import, dan pembuatan keputusan yang dapat dipilih

\section{Perancangan}

Aplikasi penunjang keputusan yang dikembangkan untuk memberikan bantuan informasi apakah perusahaan memiliki kesiapan dalam melakukan joint venture atau tidak, sehingga manajer dapat menentukan keputusan yang dilakukan dengan lebih mudah. Model yang dibuat adalah dengan membandingkan nilai harapan dari perusahaan dengan nilai aktual saat ini. Nilai harapan ini dapat merupakan nilai harapan dari perusahaan CV.ABC, maupun perusahaan yang mengajukan joint venture.

Data-data yang menjadi batasan dalam eksporimpor adalah data yang telah ditentukan oleh pihak perusahaan dalam menentukan apakah perusahaan siap melakukan joint venture atau tidak. Data yang telah ditentukan tersebut adalah data total ekspor barang dan data total impor barang yang didapat. Hasil keputusan didapatkan dari perbandingan antara data-data berikut ini:

1. Hasil ekspor dengan harapan jumlah ekspor selama tahun yang telah ditentukan sebelumnya.

2. Hasil impor dengan harapan jumlah impor selama tahun yang telah ditentukan sebelumnya.

3. Jumlah supplier dengan harapan supplier yang ditentukan oleh perusahaan.

Dari perbandingan tersebut didapatkan beberapa variasi jawaban yaitu:

1. Siap melaksanakan Joint Venture,

2. Kurang siap melaksanakan Joint Venture,

3. Sangat kurang siap melaksanakan Joint Venture, dan

4. Tidak siap Joint Venture.

\subsection{Perancangan Database}

Perancangan Database dilakukan untuk menentukan isi dan pengaturan data yang dibutuhkan dalam mengembangkan aplikasi. Database yang dikembangkan terdiri atas tabel barang, tabel supplier, tabel tujuan, tabel import, dan tabel eksport.

Tabel barang yang terlihat pada tabel 1 di bawah ini adalah hasil turunan dari ERD fisikal yang nantinya dapat digunakan untuk pengaturan data barang yang ada dan dibutuhkan oleh perusahaan.

Tabel 1. Tabel barang

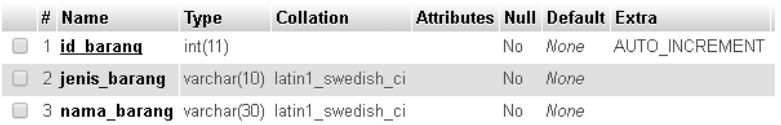

Tabel supplier yang terlihat pada tabel 2 di bawah ini adalah hasil turunan dari ERD fisikal yang nantinya dapat digunakan untuk pengaturan data supplier yang ada.

\section{Tabel 2. Tabel supplier}

\begin{tabular}{|l|lll}
\hline \# Name & Type & Collation & Attributes Null Default Extra \\
1 kode supplier & varchar(5) & latin1_swedish_ci & No None \\
2 nama_supplier & varchar(30) latin1_swedish_ci & No None
\end{tabular}

Tabel tujuan yang terlihat pada tabel 3 di bawah ini adalah hasil turunan dari ERD fisikal yang nantinya dapat digunakan untuk pengaturan data tujuan pengiriman barang yang dikirim oleh perusahaan.

\section{Tabel 3. Tabel tujuan}

$\begin{array}{llll}\text { \# Name } & \text { Type } & \text { Collation } & \text { Attributes Null Default Extra } \\ 1 \text { kode tujuan } & \operatorname{varchar(5)} & \text { latin1_swedish_ci } & \text { No None } \\ 2 \text { nama_tujuan varchar(30) latin1_swedish_ci } & \text { No None }\end{array}$

Tabel Import yang terlihat pada tabel 4 di bawah ini adalah hasil turunan dari ERD fisikal yang nantinya dapat digunakan untuk pencatatan dari pelaksanaan proses impor dari perusahaan.

\section{Tabel 4.Tabel import}

\begin{tabular}{|l|l|l|}
\hline \# Name & Type Collation Attributes Null Default Extra \\
\hline 1 kode import & int(11) & No None AUTO_INCREMENT \\
\hline 2 kode_barang & int(11) & No None \\
\hline 3 jumlah_barang int(11) & No None \\
\hline 4 harga_terima int(11) & No None \\
$\square 5$ tgl_terima varchar(30) latin1_swedish_ci & No None \\
\hline 6 kode_supplier & varchar(5) latin1_swedish_ci & No None \\
\hline
\end{tabular}

Tabel Eksport yang terlihat pada tabel 5 di bawah ini adalah hasil turunan dari ERD fisikal yang nantinya dapat digunakan untuk pencatatan dari pelaksanaan proses ekspor dari perusahaan. 


\section{Tabel 5. Tabel eksport}

\begin{tabular}{|c|c|c|c|c|c|c|c|}
\hline & \# Name & Type & Collation & Attributes & Null & Default & Extra \\
\hline $\mathrm{Q}$ & 1 kode eksport & int(11) & & & No & None & AUTO_INCREMENT \\
\hline 口 & 2 kode_barang & int(11) & & & No & None & \\
\hline D & 3 jumlah_barang & int(11) & & & No & None & \\
\hline$\square$ & 4 kode_tujuan & varchar(5) & latin1_swedish_ci & & No & None & \\
\hline 0 & 5 tgl_kirim & varchar(30) & latin1_swedish_ci & & No & None & \\
\hline$\square$ & 6 harga jual & int(11) & & & No & None & \\
\hline
\end{tabular}

Berikut ini adalah diagram yang dibuat untuk membahas hubungan antar tabel, dan data yang akan dicatat nantinya ke dalam basis data terlihat pada gambar 4 dan gambar 5 di bawah ini.

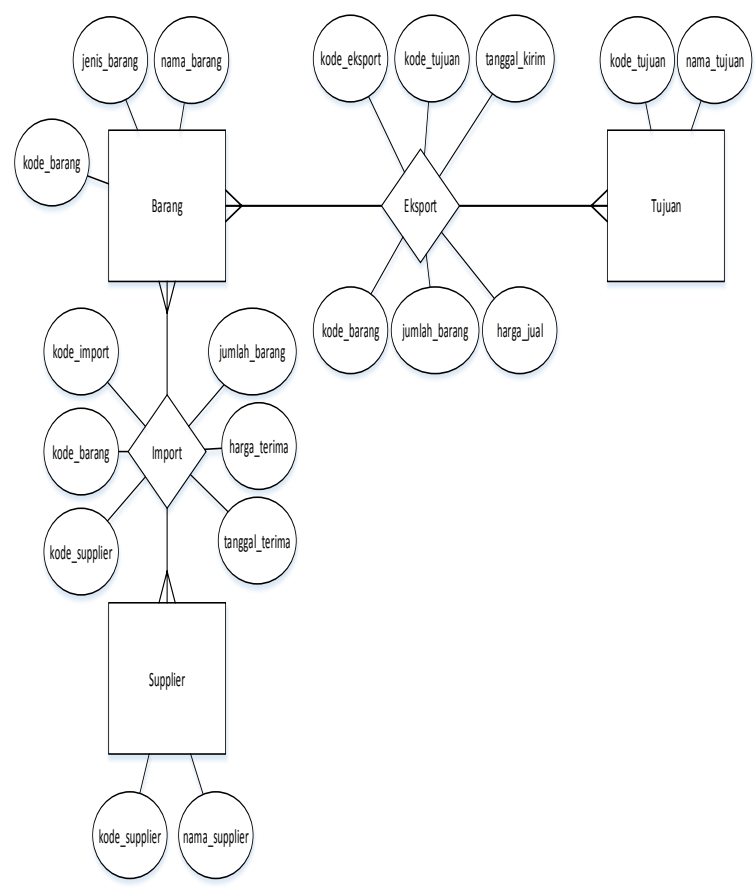

Gambar 4 ERD Konseptual

Entity Relationship Diagram (ERD) konseptula merupakan model jaringan yang menggunakan susunan data yang disimpan pada sistem secara abstrak. ERD konseptual di atas menggambarkan hubungan antara satu entitas yang memiliki sejumlah atribut dengan entitas yang lain dalam suatu sistem yang terintegrasi.

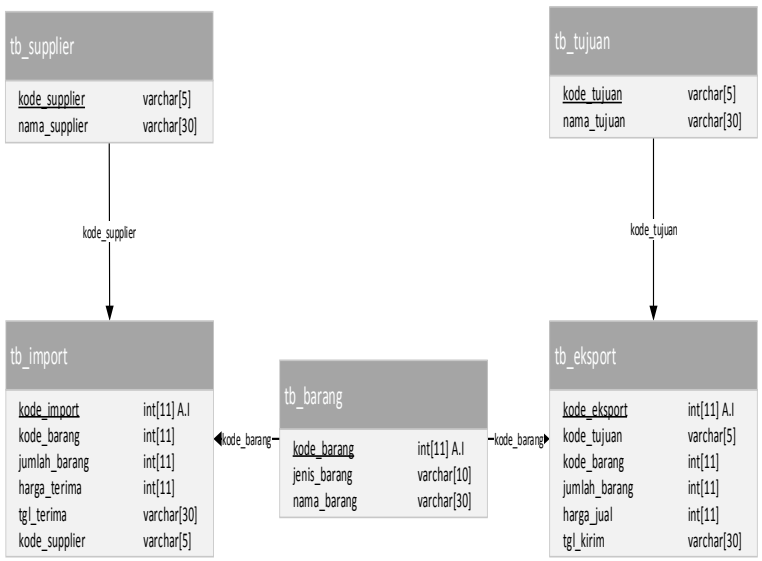

Gambar 5 ERD Fisikal

Sedangkan ERD fiskal pada gambar di atas menggambarkan deskripsi detail data disimpan ke dalam komputer. [14][15]

\subsection{Analisis Prototyping}

Prototyping yang disebutkan disini adalah pembuatan aplikasi berdasarkan fungsi masingmasingnya, sehingga dapat dicoba per proses apakah telah memenuhi kebutuhan atau tidak. Adapun gambaran alir proses yang telah didapat dari proses analisa dapat dituangkan ke dalam proses prototyping, seperti Gambar 2 di bawah ini:

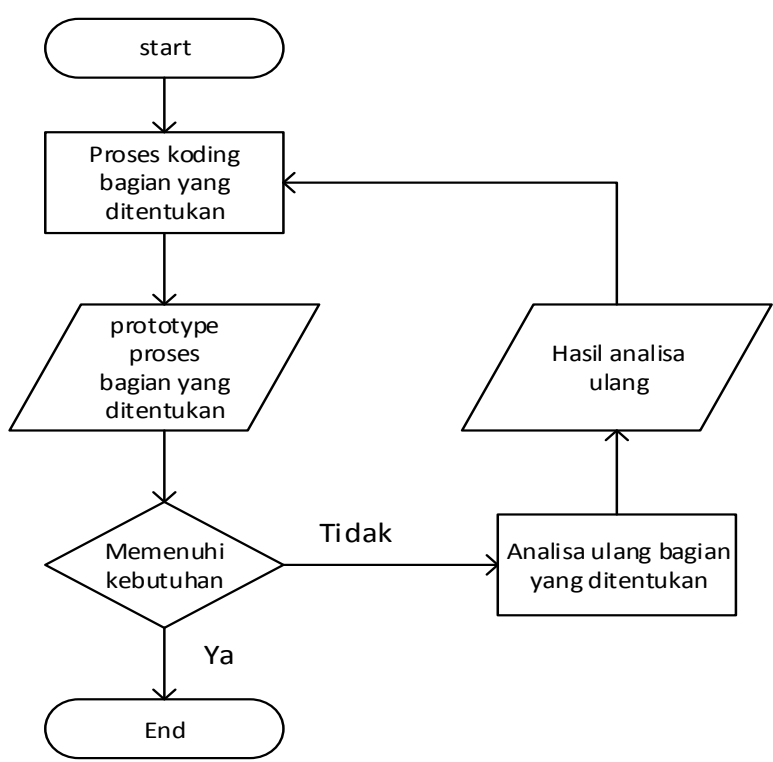

Gambar 6. Proses Prototyping 
Sesuai diagram di atas, dijelaskan bahwa dilaksanakan proses coding terhadap bagian yang telah ditentukan menghasilkan prototype dari proses tersebut, dan jika telah memenuhi kebutuhan maka proses prototype bagian tersebut telah selesai, namun jika hasil belum memenuhi kebutuhan maka dilakukan analisa ulang ke lapangan untuk menghasilkan hasil prototype yang aktual dan memenuhi kebutuhan.

\section{Implementasi}

Aplikasi penunjang keputusan joint venture yang dikembangkan adalah suatu sistem yang bersifat intranet atau hanya dapat diakses dengan penggunaan local host.

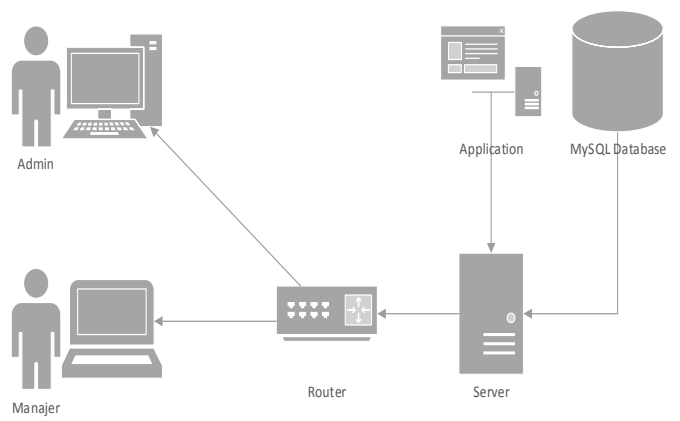

Gambar 7 Implementasi Intranet

Pada gambar 7 di atas dijelaskan bahwa ada satu server yang terkoneksi melalui router yang menjadi dasar dari pengaksesan aplikasi dan basis data MySQL. Dan yang menjadi pengakses dari sistem ini adalah admin dan manajer. Admin menggunakan PC (Personal Computer) dan manajer menggunakan laptop yang telah terhubung dengan jaringan. Aplikasi yang dibuat berisikan input, edit, view serta delete data, statistik data dan aplikasi sistem penunjang keputusan. Berikut adalah aplikasi penunjang keputusan yang dibuat terlihat pada gambar 8 dan gambar 9 di bawah ini:

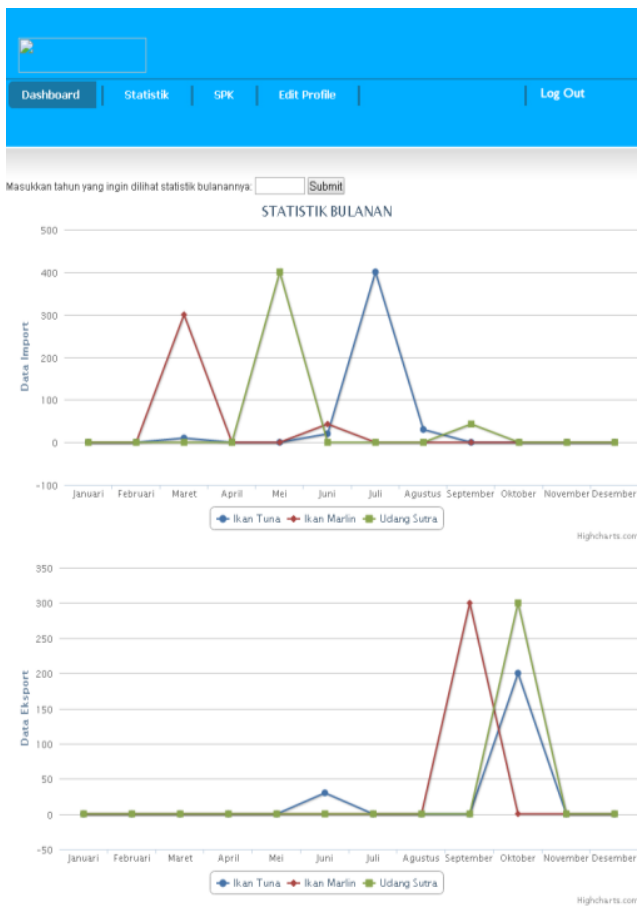

Gambar 8 Halaman Statistik Data Bulanan

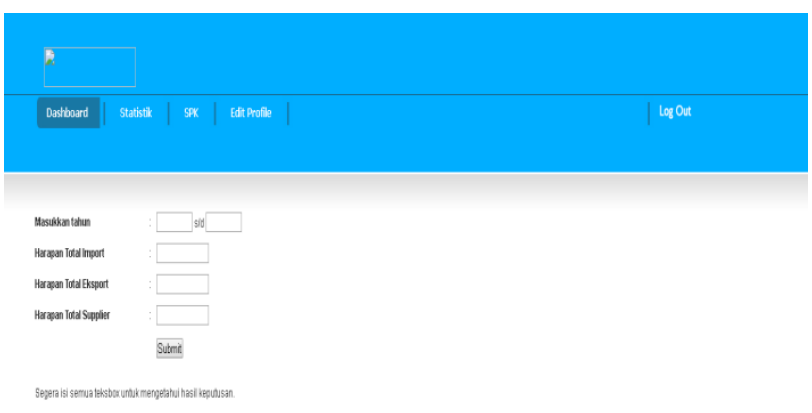

Gambar 9 Halaman Sistem Pedukung Keputusan

\section{Evaluasi}

Aplikasi ini dibuat dengan upaya memberikan bantuan informasi apakah perusahaan memiliki kesiapan dalam melakukan joint venture, sehingga manajer dapat menentukan keputusan yang dilakukan dengan lebih mudah. Hasil keputusan didapatkan dari perbandingan antara data hasil ekspor dengan harapan jumlah ekspor selama tahun yang telah ditentukan sebelumnya; hasil impor dengan harapan jumlah impor selama tahun yang telah ditentukan sebelumnya; jumlah supplier dengan harapan supplier yang ditentukan oleh perusahaan.

Untuk proses pengambilan keputusan pada dasarnya dengan prinsip memilih suatu alternatif yang terbaik. Seperti melakukan penstrukturan persoalan, penentuan alternatif-alternatif, penenetapan nilai 
kemungkinan untuk variabel antara hasil ekspor dengan harapan jumlah ekspor selama tahun yang telah ditentukan. Betapapun melebarnya alternatif yang dapat ditetapkan maupun terperincinya penjajagan nilai kemungkinan, keterbatasan yang tetap melingkupi adalah dasar pembandingan berbentuk suatu kriteria yang tunggal.

Analitycal Hierarchy Process (AHP) sebagai metode yang digunakan dengan sebuah hirarki fungsional dengan input utamanya persepsi manusia. Dengan hirarki, suatu masalah kompleks dan tidak terstruktur dipecahkan ke dalam kelomok-kelompoknya dan diatur menjadi suatu bentuk hirarki. Hal ini dapat dilakukan dengan judgement untuk menentukan peringkat dari kriteria. Dalam sebuah sistem berbasis AHP, judgement ini diberikan oleh user pengguna sistem dan dilakukan pada saat user bermaksud melakukan proses AHP dan melihat rekomendasi.

Dari perbandingan beberapa aspek tersebut, akan menghasilkan beberapa variasi jawaban, yaitu:

1. Siap melakukan joint venture.

Keputusan ini didapatkan dari hasil perbandingan dari setiap aspek data yang melebihi angka harapan yang telah ditentukan oleh manajer.

Contoh dari hasil keputusan ini adalah seperti berikut: Anda sangat siap untuk melakukan joint venture, karena Anda memiliki total import yang dilakukan dari tahun 2012 sampai tahun 2016 melebihi angka harapan Anda (20), yaitu sebesar 460KG, dan total eksport yang dilakukan dari tahun 2012 sampai tahun 2016 melebihi angka harapan Anda (20), yaitu sebesar 230KG, serta jumlah supplier melebihi angka harapan Anda, yaitu 1.

2. Kurang siap melakukan joint venture.

Keputusan ini didapatkan karena adanya salah satu aspek yang tidak memenuhi angka harapan yang ditentukan oleh perusahaan.

Tabel 6 Perbandingan keputusan kurang siap

\begin{tabular}{|c|c|c|c|}
\hline Aspek & 1 & 2 & 3 \\
\hline Total Impor & $\mathrm{X}$ & & \\
\hline Total Ekspor & & $\mathrm{x}$ & \\
\hline Total Supplier & & & $\mathrm{x}$ \\
\hline
\end{tabular}

Pada table 6 di atas dijelaskan bahwa ada 3 kemungkinan yang membuat hasil keputusan kurang siap melakukan joint venture, yaitu:

a. Total impor yang kurang dari angka harapan.

Contoh dari hasil keputusan ini adalah sebagai berikut:
Anda kurang siap untuk melakukan joint venture, karena Anda memiliki total impor yang dilakukan dari tahun 2012 sampai tahun 2016 di bawah angka harapan Anda (600), yang hanya $460 \mathrm{KG}$, tetapi total ekspor yang dilakukan dari tahun 2012 sampai tahun 2016 melebihi angka harapan Anda (20), yaitu sebesar 230KG, serta jumlah supplier melebihi angka harapan Anda, yaitu 1.

b. Total ekspor yang kurang dari angka harapan.

Contoh dari hasil keputusan ini adalah sebagai berikut:

Anda kurang siap untuk melakukan joint venture, karena Anda memiliki total ekspor yang dilakukan dari tahun 2012 sampai tahun 2016 di bawah angka harapan Anda (600), yang hanya $460 \mathrm{KG}$, tetapi total ekspor yang dilakukan dari tahun 2012 sampai tahun 2016 melebihi angka harapan Anda (20), yaitu sebesar 230KG, serta jumlah supplier melebihi angka harapan Anda, yaitu 1.

C. Total supplier yang kurang dari angka harapan.

Contoh dari hasil keputusan ini adalah sebagai berikut:

Anda kurang siap untuk melakukan joint venture, karena jumlah supplier di bawah angka harapan Anda, hanya 1, tetapi Anda memiliki total impor yang dilakukan dari tahun 2012 sampai tahun 2016 melebihi angka harapan Anda (20), yaitu sebesar $460 \mathrm{KG}$, serta total ekspor yang dilakukan dari tahun 2012 sampai tahun 2016 melebihi angka harapan Anda (20), yaitu sebesar 230KG.

3. Sangat kurang siap melakukan joint venture.

Keputusan ini didapatkan karena adanya dua aspek yang tidak memenuhi angka harapan yang ditentukan oleh perusahaan.

Tabel 7 Perbandingan keputusan sangat kurang siap

\begin{tabular}{|c|c|c|c|}
\hline Aspek & 1 & 2 & 3 \\
\hline Total Impor & $\mathrm{X}$ & & $\mathrm{x}$ \\
\hline Total Ekspor & $\mathrm{X}$ & $\mathrm{x}$ & \\
\hline Total Supplier & & $\mathrm{x}$ & $\mathrm{x}$ \\
\hline
\end{tabular}

Pada tabel 7 di atas dijelaskan bahwa ada 3 kemungkinan yang membuat hasil keputusan sangat kurang siap melakukan joint venture, yaitu:

a. Total impor dan total ekspor yang kurang dari angka harapan.

Contoh dari hasil keputusan ini adalah sebagai berikut: 
Anda sangat kurang siap untuk melakukan joint venture, karena anda memiliki total impor yang dilakukan dari tahun 2012 sampai tahun 2016 di bawah angka harapan Anda (600), yang hanya 460KG, dan jumlah supplier di bawah angka harapan Anda, hanya 1, tetapi total eksport yang dilakukan dari tahun 2012 sampai tahun 2016 melebihi angka harapan Anda (20), yaitu sebesar 230KG.

b. Total ekspor dan total supplier yang kurang dari angka harapan.

Contoh dari hasil keputusan ini adalah sebagai berikut:

Anda sangat kurang siap untuk melakukan joint venture, karena total ekspor yang dilakukan dari tahun 2012 sampai tahun 2016 di bawah angka harapan Anda (600), yang hanya $230 \mathrm{KG}$, dan jumlah supplier di bawah angka harapan Anda, hanya 1, tetapi Anda memiliki total impor yang dilakukan dari tahun 2012 sampai tahun 2016 melebihi angka harapan Anda (20), yaitu sebesar 460KG.

c. Total impor dan total supplier yang kurang dari angka harapan.

Contoh dari hasil keputusan ini adalah sebagai berikut

Anda tidak siap untuk melakukan joint venture, karena Anda memiliki total impor yang dilakukan dari tahun 2012 sampai tahun $2016 \mathrm{di}$ bawah angka harapan Anda (600), yang hanya $460 \mathrm{KG}$, dan total ekspor yang dilakukan dari tahun 2012 sampai tahun 2016 di bawah angka harapan Anda (600), yang hanya 230KG, serta jumlah supplier di bawah angka harapan Anda, hanya 1.

\section{Tidak siap melakukan joint venture.}

Keputusan ini didapatkan karena semua aspek tidak memenuhi harapan yang diberikan oleh perusahaan.

Contoh dari hasil keputusan ini adalah sebagai berikut

Anda sangat kurang siap siap untuk melakukan joint venture, karena Anda memiliki total impor yang dilakukan dari tahun 2012 sampai tahun 2016 di bawah angka harapan Anda (600), yang hanya $460 \mathrm{KG}$, dan total ekspor yang dilakukan dari tahun 2012 sampai tahun 2016 di bawah angka harapan Anda (600), yang hanya 230KG, serta jumlah supplier di bawah angka harapan Anda, hanya 1.

\section{Simpulan}

Dengan membandingkan data yang dimiliki perusahaan dalam aspek total impor barang, total ekspor barang dan total supplier dengan nilai angka harapan yang diberikan oleh perusahaan maka akan memberikan hasil keputusan yang dapat membantu manajer dalam menentukan apakah perusahaan memiliki kesiapan dalam melakukan joint venture atau tidak.

Adapun hasil-hasil keputusan yang dapat dihasilkan diantaranya sangat siap melaksanakan Joint Venture, kurang siap melaksanakan Joint Venture, sangat kurang siap melaksanakan Joint Venture, dan tidak siap melaksanakan Joint Venture.

\section{Referensi}

Asfi, M dan Ratna P.S. (2010) Sistem Penunjang Keputusan Seleksi Mahasiswa Berprestasi Menggunakan Metode AHP (Studi Kasus: STMIK CIC Cirebon). Jurnal Informatika, Vol.6, No.2, Desember 2010: 131 - 144.

Ernawati., N, Elvi ., (2017) Rancang Bangun Sistem Pendukung Keputusan Kenaikan Jabatan Pegawai dengan Metode Profile Matching (Studi kasus:Kementrian Agama Kantor wilayah Jakarta Barat), Studia Informatika: Jurnal Sistem Informasi 10 (2), pp 127-134.

Faisal.S., Permana.D.H, (2015) Sistem Penunjang keputusan pemilihabn Sekolah Menengah Kejuruan Teknik Komputer dan Jaringan yang Terfavorit dengan Menggunakan Multi-Criteria Decision Making, Jurnal Teknologi Informasi dan ilmu Komputer (JTIIK) Vol.2 No.1, pp.11-19

Tominanto. (2010) Sistem Pendukung Keputusan dengan Metode Analytical Hierarchy Process (AHP) untuk Penentuan Prestasi Kinerja Dokter pada RSUD. Sukoharjo. INFOKES, VOL. 2 NO. 1 Agustus 2012 ISSN :2086 - 2628.

Sasongko.A., dkk (2017) Pemilihan Karyawan Baru dengan Metode AHP, Jurnal Informatika Mulawarman Vol.12 No.2.

Turban.E.,dkk (2007) Decision Support Systems and Intelligent Systems $7^{\text {th }}$ edition. New Delhi: Prentice-Hal! of India.

Whitten, J.L. dkk. (2007) Systems Analysis and Design Methods. $7^{\text {th }}$ ed. Indianapolis: McGraw-Hill Education.

Ernawati, N.A., Fetrina, E., (2017) Rancang Bangun Sistem Pendukung Keputusan Kenaikan Jabatan Pegawai dengan Metode Profile Matching (Studi kasus:Kementrian Agama Kantor wilayah Jakarta Barat), Studia Informatika: Jurnal Sistem Informasi 10 (2), pp 127-134. 
Widjaja, H, Hayat.C., (2015) Analisis dan Perancangan Aplikasi Pemilihan Jenis Beasiswa menggunakan Metode Analytical Hierarchy process (Studi kasus beasiswa UKRIDA), Jurnal Teknik dan Ilmu Komputer Vol.4 No.13

Mahdalena, R. (2018) Sistem Pendukung Keputusan penentuan Mahasiswa Lulusan terbaik Menggunakan Metode AHP pada Perguruan Tinggi. Jurnal Matrik penusa Vol.2 No.1 Juni, pp $1-10$.

Ferawati,M.K (2015) "Impelemtasi Metode Analytical Hierarchy Process (AHP) dalam Sistem Pendukung Keputusan untuk Penerimaan Raskin di kelurahan Simpang Baru Panam, Jurnal SATIN - Sains dan Teknologi Informasi Vol.1 No.1.

Chan, A.S. (2019) Sistem Pendukung Keputusan Pemilihan Karyawan Berprestasi pada PT. Fast
Food Indonesia Cabang Batam dengan Menggunakan Metode Analytical Hierarchy Process, Jurnal SATIN - Sains dan Teknologi Informasi Vol.3 No.1.

Bagui.S dkk (2012). Database Design Using EntityRelationship Diagrams, Second Edition. Florida: Taylor \& Francis Group, LLC.

Saefudin.S (2014) Sistem Pendukung Keputusan untuk Penilaian Kinerja Pegawai menggunakan Metode AHP pada RSUD Serang, Jurnal Sistem Informasi Vol.1 No.1.

Mufizar.T dkk., (2017) Sistem Pendukung Keputusan dalam Penentuan Pertukaran Pelajar di SMA Negeri 2 Tasikmalaya dengan metode AHP, Cogito Smart Journal Vol 3 No.1 